\title{
Antimicrobial Resistance: An Emerging Threat to Public in Nepal
}

\author{
Uday Narayan Yadav ${ }^{1 *}$, Narayan Dutt Pant ${ }^{2}$, Roshan Thapa ${ }^{3}$, Rosham Manjhi ${ }^{4}$ \\ ${ }^{1}$ Research and Evaluation, Forum for Health Research and Development, Nepal \\ ${ }^{2}$ Department of Microbiology, Grande International Hospital, Kathmandu, Nepal \\ ${ }^{3}$ Central Department of Microbiology, Tribhuvan University, Kathmandu, Nepal \\ ${ }^{4}$ Microbiology, National Public Health Laboratory, Kathmandu, Nepal
}

Received: December 08, 2016; Accepted: December 14, 2016; Published: December 20, 2016

*Corresponding author: Uday Narayan Yadav, Forum for Health Research and Development. Tel: +977-9862077067 E-mail: unyadav1@gmail.com

\begin{abstract}
Antimicrobial resistance is an emerging public health issue in developing countries like Nepal. The underlying causes may be lack of awareness among the public about the rationale use and correct dose of antibiotics, haphazard use of antibiotics, unnecessary prescriptions by the doctors/ health professionals, non-standard frequency of administration and treatment duration and free availability of drugs (without prescription). This paper aimed to briefly highlight the situation of antimicrobial resistance, co-ordination gaps among the stakeholders and steps forward to tackle problem of increasing antimicrobial resistance in Nepal.
\end{abstract}

Keywords: Antimicrobial resistance; Antibiotics; Self-medication

\section{Introduction}

Though the development of antibiotic resistance is a natural process, haphazard use of antibiotics will hasten the rate of emergence of drug resistant bacteria due to selective pressure. According to World Health Organization (WHO) report, less than $40 \%$ of patients in public health facilities and less than $30 \%$ of those in the private healthcare settings are treated according to appropriate clinical guidelines [1]. The increase in drug resistance among bacteria has created a serious problem to the public health. The antibiotics are becoming ineffective because of lack of awareness among the public about its rationale use and correct dose, haphazard use, unnecessary prescriptions by the doctors/ health professionals, non-standard frequency of administration and treatment duration and free availability of drugs (without prescription) in most of the developing countries including Nepal. However, bacterial resistance to antibiotics occurs even without the use of antibiotics [2, 3].

\section{Country Context}

The self-medication is very common in Nepal and the patients go to the doctor only after they become unsuccessful to cure themselves [4]. The high antimicrobial resistance burden is not only due to irrational use of antibiotics among humans but also among the animals.

Few studies conducted to study drug resistance bacteria among food animals and animal products in Nepal have documented the high rates of drug resistance among the bacteria isolated [5]. The reason for this may be the use of antibiotics as growth promoter in animals [5]. In Nepal, the antimicrobial resistance surveillance was started in 1999 A.D; however there is no coordination between human and veterinary health workers to reflect the actual burden of the problem in the country. But it can be concluded from the literature review of all the published data from Nepal that the situation of drug resistance among bacteria is very bad.

If the appropriate steps are not put forward immediately, the arrival of post antibiotic era is inevitable, when the patient will die even with the infections which are considered minor. In Nepal, the antimicrobial resistance surveillance is not up to the mark, since its commencement. There is an urgent need of collaboration between Department of Health Services (Ministry of Health), Department of livestock services (Ministry of Livestock Development) and Ministry of Population and Environment for having joint surveillance program. The action is in process to train human resources of healthcare service but there is no such practice for veterinary and agricultural human resources in Nepal.

Steps Forward: Community based awareness programs must be implemented to develop awareness among the public about the rationale use of antibiotics and the factors contributing to antibiotic resistance and its spread to food chain. The public must also be made aware of having complete course if under medication, avoiding self-medication and stopping the overuse of antibiotics.

Furthermore, strict monitoring of pharmacists is necessary and policy should be made where pharmacists are allowed to sell the drugs only as per medical doctor's prescriptions because in context of Nepal, community medical assistant, health assistant and other health manpowers haphazardly prescribe medicines 
at the community level. Furthermore, in health care settings implementation of antimicrobial stewardship program may limit the haphazard use of antibiotics, hence controlling the situation of drug resistance from worsening [6].

But in case of Nepal no such programs have been known to be implemented and even if it is tried it will be very difficult due to lack of resources and skilled manpowers. Further the concept of "I know all" mostly among the well-established and senior clinicians will cause a serious problem to the implementation of the antimicrobial stewardship program in Nepal and a war is needed to be fought by the concerned authorities make the clinicians understand the importance of the program.

\section{Conclusions}

There is an urgent need of awareness program on antimicrobial resistance in Nepal and attention must be paid by the stakeholders to close co-ordination gaps among them and to curb the problem of increasing antimicrobial resistance.

\section{References}

1. World Health Organization. The world medicines situation 2011. Rational use of medicines. 3rd ed. Geneva, Switzerland: WHO; 2011.

2. Bruycker MD, Bergh RVD, Dahmane A, Khogali M, Schiavetti B, Nzomukunda $Y$, et al. Non-adherence to standard treatment guidelines in a rural paediatric hospital in Sierra Leone. PHA. 2013;3(2):1-7.

3. Golkar Z, Bagazra O, Pace DG. Bacteriophage therapy: a potential solution for the antibiotic resistance crisis. J Infect Dev Ctries 2014;8(2):129-136.

4. Thakur S, Pokhrel N, Sharma M. Prevalence of Multidrug Resistant Enterobacteriaceae and Extended Spectrum $\beta$ Lactamase Producing Escherichia Coli in Urinary Tract Infection. Res J Pharma BiolChem Sci. 2013;4(2):1615-1624.

5. Basnyat B,Pokharel P,Dixit S,Giri S. Antibiotic Use, Its Resistance in Nepal and Recommendations for Action: A Situation Analysis. J Nepal Health Res Counc. 2015;13(30):102-111.

6. MacDougall C, Polk RE. Antimicrobial stewardship programs in health care systems. ClinMicrobiol Rev. 2005;18(4):638-656. 